\title{
Extensive Angiolymphoid Hyperplasia with Eosinophilia with Severe Anemia and Uncontrolled Diabetes Mellitus
}

\author{
Shreya Dass*and Meena Makhecha \\ Department of Dermatology, Venereology and Leprology, HBT Medical College and Dr. RN Cooper Municipal General Hospital, India
}

Received: April 20, 2018; Published: May 03, 2018

*Corresponding author: Shreya Dass, Department of Dermatology, Venereology and Leprology, HBT. Medical College and Dr. RN Cooper Municipal General Hospital, India

Abstract

A 57-year-old male presented with multiple it chypurple raised lesions on left side off ace and scalp for 3 years. Examination revealed multiple soft to firm violaceous papules and nodules, varying in size from $0.5 \mathrm{cmto} 1 \mathrm{~cm}$, limited to left side of scalp and face over forehead, periorbital, preauricular, anterior helix, post auricular and beard are as with few excoriations. There was no associated regional lymphadenopathy. Laboratory reports: Haemoglobin $=5.7 \mathrm{gm} \%$, decreased red cell count and indices, increased red cell distribution width, leukocytosis elevated blood sugars(Fasting Blood Sugar=430mg\%),decreased serum ferritin and normal serum Immunoglobulin E (IgE). Histopathology revealed increased thick-walled capillaries and venules in upper dermis surrounded by an infiltrate of lymphocytes and eosinophils with their linings how in gplumpendo the lialcells. High frequency ultra-sonography of affected skin suggested enlarged lymphnodes. Angiolymphoid Hyperplasia with Eosinophiliaisa rare entity; and extensive involvement with severe uncontrolled diabetes mellitus and severe anemia, along withfeaturesoverlappingwithKimura'sdiseasehasnotbeenreportedpreviously.

Keywords: Angiolymphoid Hyperplasia with Eosinophilia; Kimura's Disease; Scalp and Face Nodules

\section{Introduction}

Angiolymphoid hyperplasia with eosinophilia (ALHE), a rare benign vascular proliferation, was initially thought to be a late stage of Kimura's disease, is now considered a separate entity. We report a case of ALHE with extensive ( $>50$ ) lesions, severe anemia $($ Haemoglobin $=5.7 \mathrm{gm} \%)$ and severe uncontrolled diabetes mellitus (Fasting Blood Sugar $=430 \mathrm{mg} \%$ ). These associations have not been reported previously. Our patient also had lymphadenopathy, a feature of Kimura's disease.

\section{Case Report}

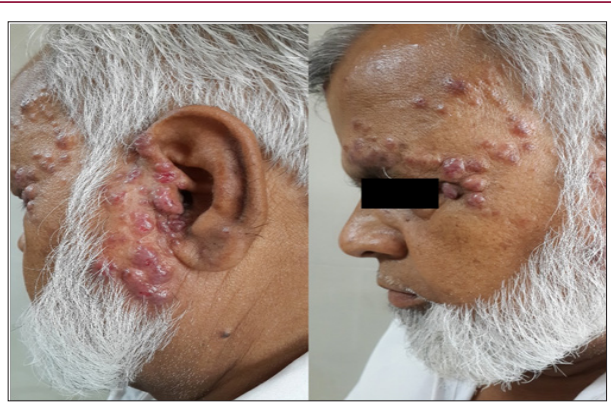

Figure 1: Multiple violaceous papules and nodules on left side of face with few excoriations.

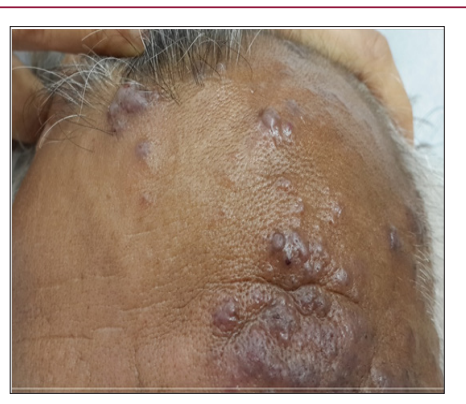

Figure 2: Multiple violaceous papules coalescing to form plaque on left side of forehead and papules on left side of scalp.

A57-year-old male, uncontrolled diabetic presented with complaints of multiple itchy purple raised lesions on left side of face for three years, with a history of bleeding on trauma. Lesions started as few pink-purple nodules over left preauricular region and gradually increased in size and numbers since then. No history of pain, similar lesions on the other side of face or elsewhere on body was noted. One examination multiple violaceous papules and nodules, ranging in size from 0.5 centimeter to one centimeter, 
limited to left side of scalp and face were noted. Lesions were soft to firm in consistency and slightly tender. Few excoriations were present. No lymphadenopathy or salivary gland enlargement was noted (Figures 1 \& 2).

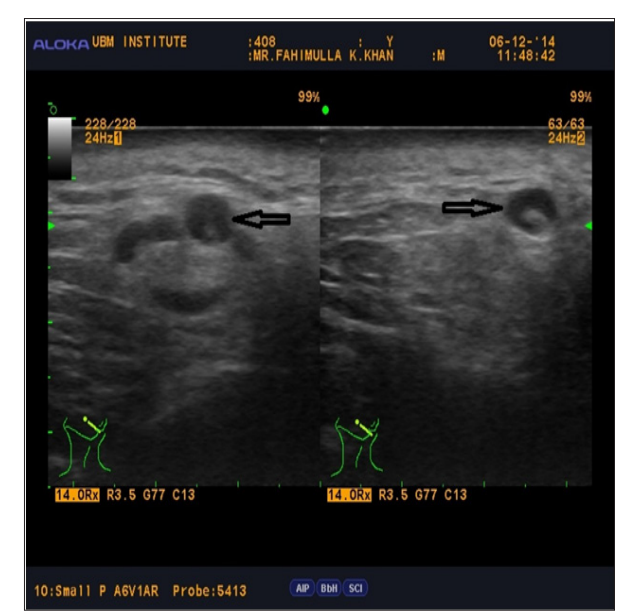

Figure 3: High frequency ultrasonography of skin demonstrating well defined hypo echoic masses (suggestive of enlarged lymph nodes) in preauricular region.

Laboratory investigations revealed severe anemia (Haemoglobin=5.7gm\%), decreased red cell indices (Mean Corpuscular Volume=59.7 femtoliters, Mean Corpuscular Haemoglobin=15.5picograms, Mean Corpuscular Haemoglobin Concentration=26.0grams/deciliter, Packed Cell Volume $=21.9 \%$ ), increased red cell distribution width (15.9\%), leucocytosis (11,900percubicmillimeter) and elevated fasting blood sugar levels(430milligram percent).Eosinophils (4\%), liver and renal function tests, serum IgE levels were normal. The serology was negative for antibodies to Human Immuno deficiency Virus (HIV)and Hepatitis-C virus. High frequency ultrasonography of skin revealed multiple nodular hypo echoic mass lesions in sub epidermal region (suggestive of lesions) and few well defined hypo

\section{Discussion}

\section{Table 1.}

\begin{tabular}{|c|c|c|c|}
\hline Feature & ALHE & Kimura's ds. & Our Patient \\
\hline Epidemiology & Young to middle age $(\mathrm{F}>\mathrm{M})$ & Young adults $(\mathrm{M}>\mathrm{F})$ & Elderly male (57years) \\
\hline Symptoms & Pain, pruritus, pulsatile & Asymptomatic & Pruritus (+) \\
\hline $\begin{array}{l}\text { Characteristic of lesions (papules } \\
\text { and nodules) }\end{array}$ & $\begin{array}{c}\text { Small, superficial with overlying } \\
\text { erythema (+) }\end{array}$ & $\begin{array}{l}\text { Large, deep with subcutaneous } \\
\text { extension, overlying skin normal }\end{array}$ & $\begin{array}{c}\text { Few small superficial, few large and } \\
\text { deep, overlying erythema }(+)\end{array}$ \\
\hline $\begin{array}{l}\text { Lymphadenopathy and salivary } \\
\text { gland involvement }\end{array}$ & Absent & Present & $\begin{array}{l}\text { Clinically absent but USG skin } \\
\text { revealed lymph node involvement. } \\
\text { No salivary gland involvement. }\end{array}$ \\
\hline Eosinophilia & $<20 \%$ cases & Present & Absent \\
\hline Serum ige levels & Normal & Elevated & Normal \\
\hline $\begin{array}{l}\text { Lymphoid follicles (on } \\
\text { histopathology) }\end{array}$ & Uncommon & Prominent with germinal centers & Absent \\
\hline Vascular proliferation & $\begin{array}{l}\text { Prominent with plump endothelial } \\
\text { cells.Underlying A-V malformation } \\
\text { may be seen. }\end{array}$ & $\begin{array}{l}\text { Some stromal vascularity with } \\
\text { unremarkable endothelial cells. }\end{array}$ & $\begin{array}{l}\text { Prominent with plump endothelial } \\
\text { cells.No A-V malformation seen. }\end{array}$ \\
\hline Fibrosis & Absent or limited & Prominent & Absent \\
\hline Renal involvement & Absent & Present in up to $20 \%$ cases & Absent \\
\hline
\end{tabular}

echoic masses with an echogenic center (suggestive of enlarged lymphnodes) in preauricular region (Figure 3).

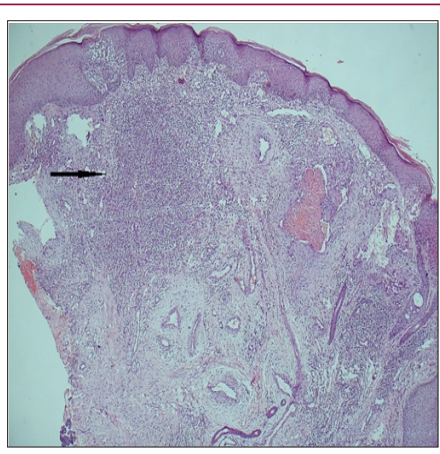

Figure 4: Proliferation of small - medium sized vessels showing lobular architecture (H \& E 4X).

Parotidgland and subcutaneous tissue was normal. No ArterioVenous malformation was seen on colour and pulsed Doppler. Histopathology revealed proliferation of small and medium sized vessels showing lobular architecture with perivascular inflammatory infiltrate of lymphocytes and eosinophils. Their lining showed plump endothelial cells with abundant eosinophilic cytoplasm and intracytoplasmic vacuoles (Figures $4 \& 5$ ).

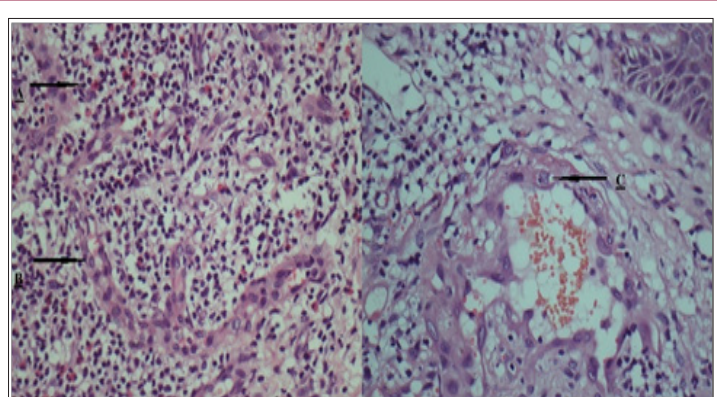

Figure 5: A.Perivascular inflammatory infiltrate of lymphocytes and eosinophils. B. Plump endothelial cells with abundant eosinophilic cytoplasm. C. Endothelial cell showing intracytoplasmic vacuoles. (H \& E 40X). 
Angiolymphoid hyperplasia with eosinophilia (ALHE) is a rare benign but potentially disfiguring vascular proliferation. It was first described by Wells and Whimster in 1969 [1]. They considered it to be a late stage of Kimura's disease, adisorder described in the Japanese literature twenty years earlier. Currently, however, most authors believe that ALHE and Kimura's disease are two separate entities [2,3]. Our patient had most features of ALHE with lymphadenopathy, which is a feature of Kimura's disease. The epidemiological, clinical and histopathological differences between the two entities along with features present in our patient are summarized in the table (Table1).

Were port and emphasize this case considering these unusual features:

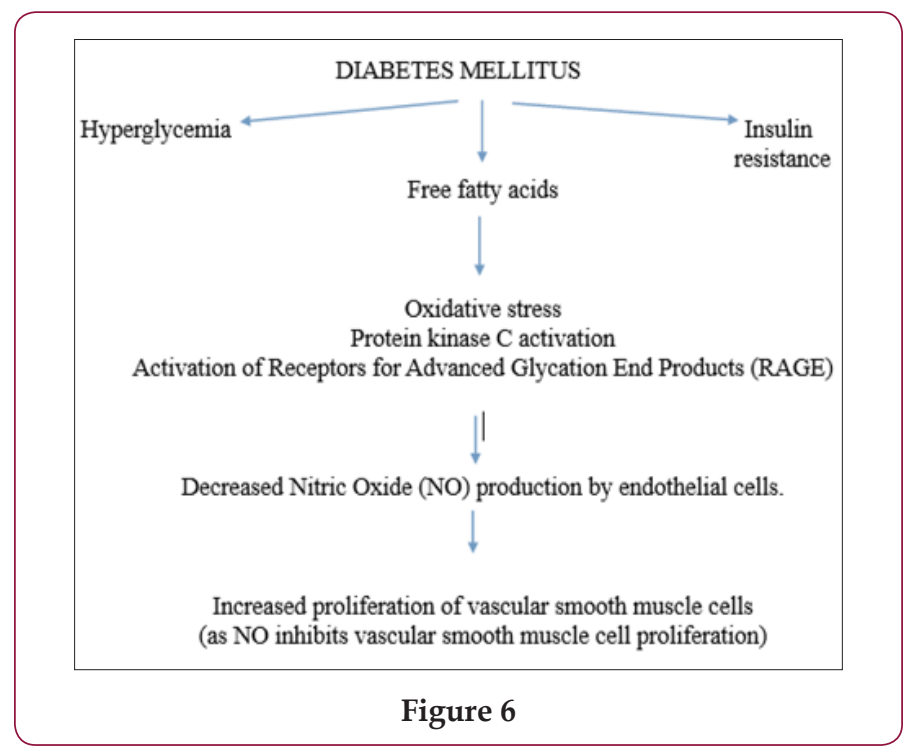

Extensive lesions ( $>50)$ associated with severe uncontrolled diabetes mellitus (DM): The association of DM with ALHE has not been reported in literature so far. Also, there is anyone case report of a patient (non-diabetic) with extensive lesions [1]. The association of DM with various macro and microvascular abnormalities has long been known and the major cells affected are endothelial cells and vascular smooth muscle cells as depicted in the Figure $6[4,5]$. Whether this endothelial and vascular smooth muscle cell dysfunction has any role to play in vascular proliferation seen in ALHE needs to be proved with further reports and studies.
Severe unexplained anaemia ( $\mathrm{Hb}$ 5.7gm\%): After thorough evaluation by an expert haematologist, no underlying cause for severe anomie was found except bleeding from the lesions. Hence chronic blood loss (even though very little) from the lesions may lead to severe anaemia and hence haemoglobin in should be monitored. Our patient was treated with three injections of ferritin carboxymaltose (two on day one followed by one on day seven) following which $\mathrm{Hb}$ was noted $9.40 \mathrm{gm} \%$.

With lymphadenopathy which is a feature of Kimura's disease.

\section{Conclusion}

ALHE is a rare entity and such extensive involvement with severe uncontrolled diabetes mellitus and with severe anemia has not been reported previously. Monitoring of haemoglobin and blood sugars may be advisable inpatients with extensive lesions.

\section{Key Messages}

a) Extensive lesions of Angiolymphatic Hyperplasia with Eosinophilia may cause severe anaemia, hence haemoglobin in must be monitored in such cases.

b) Uncontrolled diabetes mellitus may be associated with increased severity of the disease.

\section{References}

1. Ahmad SM, WaniGM, Khursheed B, Qayoom S (2014) Angiolymphoid hyperplasia with eosinophilia mimicking multiple cylindromas:a rare case report. Indian J Dermatol 59(4): 423.

2. GoogePB, Harris NL, Mihm MC Jr (1987) Kimura's disease and angiolymphoidhyperplasia witheosinophilia: Two distinct histopathological entities. J Cutan Pathol 14(5): 263-271.

3. Kung IT, Gibson JB, Bannatyne PM (1984) Kimura's disease: A clinicopathological study of 21 cases and its distinction from angiolymphoid hyperplasia with eosinophilia. Pathol 16(1): 39-44.

4. Paneni F, Beckman JA, Creager MA, Cosentino F (2013) Diabetes and vascular disease: pathophysiology,clinical consequences, and medical therapy: part I. Eur Heart J 34(31): 2436-2443.

5. Hadi HA, Suwaidi JA (2007) Endothelial dysfunction in diabetes mellitus. Vascular Health and Risk Management 3(6): 853-876.
This work is licensed under Creative Commons Attribution 4.0 License

Submission Link: https://biomedres.us/submit-manuscript.php

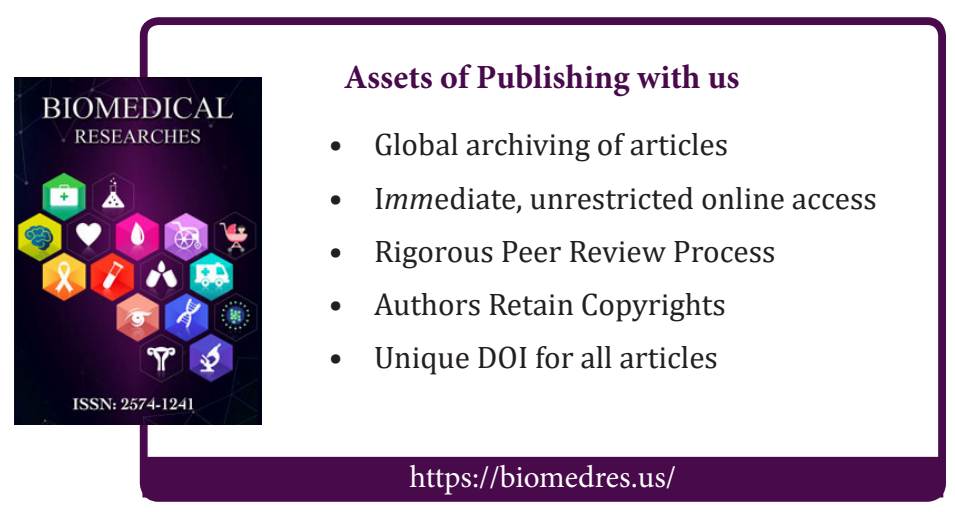

